Efficiency of TSA/Thio as a Culture Medium compared with TSA/TSB and Ox Bile

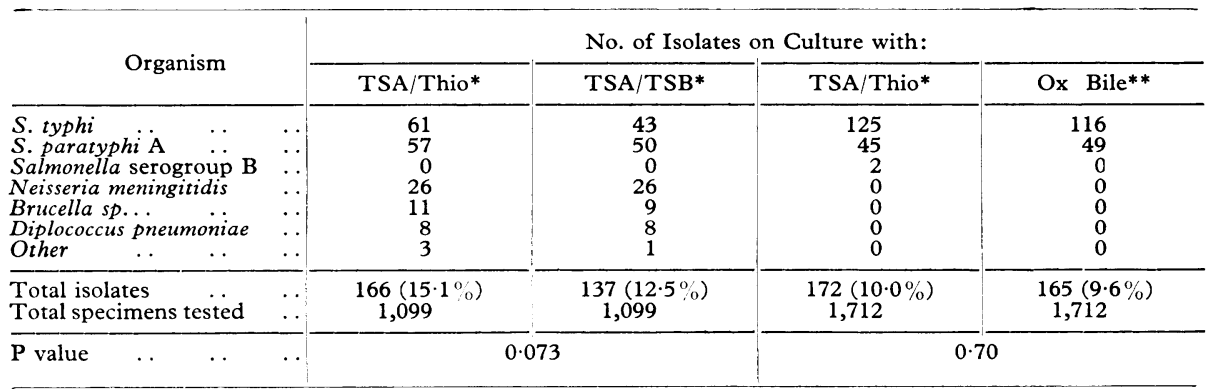

*Inoculated with $5 \mathrm{ml}$ of patient's blood. Incubated for up to 14 days.

**10 $\mathrm{ml}$ of ox bile inoculate with $3 \mathrm{ml}$ of patient's blood. Subcultured on Trypticase soy agar plates on days 1, 3 and 7 .

similar system (TSA/TSB) that was composed of trypticase soy agar and trypticase soy broth (BBL) with Grobax (sodium polyanethol sulphonate; Roch Diagnostics) and antibiotic inhibitors and which was gassed with a mixture of $5 \%$ carbon dioxide and $95 \%$ air. $^{2}$ TSA/Thio was also found to be as efficient as ox bile $(10 \%)$ in the isolation of salmonella.

We have diagnosed 272 cases of typhoid and paratyphoid fever, 14 of brucellosis, and 30 of meningococcaemia by culture with TSA/Thio during the past year. We think it is an excellent system for routine blood culture in areas endemic for these diseases. -We are, etc.

J. E. SIPPEL U.S. Naval Medical Research Unit No. 3 , Cairo, Egypt

ABDulla S. Diab

The University of Alexandria,

A. Ellakani

Alexandria, Egypt

1 Castaneda, M. R., Proceedings of the Society for Experimental Biology and Medicine, 1947, 64, 2 Sanborn, W. R., and Dyer, J. C., Fournal of the Egyptian Public Health Association, 1970, 45,

\section{Place of Diagnostic Radiology in Medicine}

Sir,-Like Dr. A. S. Bligh (14 September, p. 684), I am disappointed with the lack of correspondence following the article by Dr. J. W. D. Bull on the place of diagnostic radiology in medicine (10 August, p. 394). The serious situation he discussed is known to radiologists throughout the country. Repeatedly one hears of difficulties in obtaining equipment and problems with outof-date $x$-ray departments, much bigger work loads, and fewer staff. It has been shown in Scandinavia and, more recently, in the United States that radiology holds a prior position in diagnostic services. Our administrative and medical colleagues in the National Health Service have failed to give it financial priority.

Like Dr. Bull, I believe that the difficulty in promoting postgraduate interest in radiology partly results from our failure to establish a satisfactory programme for teaching it to undergraduates. There is a place for using our radiological training in both the preclinical and clinical years. Radiologists should take part in teaching anatomy, physiology, and pathology as well as clinical subjects, and in postgraduate education radiology has a place in almost all specialties. A satisfactory teaching programme will require more teachers as well as upgraded departments. Plans to establish chairs in radiology should be actively supported by deans of medical schools and by all radiologists and their medical and surgical colleagues. To postpone action will perpetuate a radiological service that is inferior to that in Europe and the United States.

There is now a serious "radiological drain" to other countries. This must be checked and recruitment into the specialty increased. Academic departments, by undergraduate and postgraduate teaching and by their interest in research, would hopefully stimulate a new interest among young doctors in radiology as a career. An enthusiastic, sustained, and vociferous effort is needed from all who are interested in our subject.-I am, etc.

St. Mary's Hospital,

OSCAR CRAIG

\section{Comparison between Free Thyroxine Index} and Effective Thyroxine Ratio

SIR,-Like Dr. E. G. M. D'Haene and others (21 September, p. 708) we too are interested in the relationship between effec- tive thyroxine ratio (E.T.R.) and free thyroxine index (F.T.I.). Despite the literature referred to by the authors we suggest the approach to the determination of the E.T.R./F.T.I. relationship should be as follows.

The E.T.R. reflects serum thyroxine (T-4) levels and automatically compensates to a large extent for variations in thyroxinebinding globulin (T.B.G.) capacity. ${ }^{1}$ If T.B.G. concentration showed no variation in the normal population, then the value for the E.T.R. would be determined entirely by the level of T-4. For this reason there is a very high linear correlation between E.T.R. and T-4 when patients with T.B.G. abnormalities are excluded.

In a recent study we measured $\mathrm{T}-4$ using Thyopac 5 and absolute free thyroxine concentration (A.F.T-4), by the method of Sterling and Brenner ${ }^{2}$ in 180 consecutive patients who were not suspected of having T.B.G. abnormalities. The results (fig. 1) show clearly that T-4 and A.F.T-4 are not linearly related. E.T.R. values were also obtained in these patients and as expected the E.T.R./A.F.T-4 correlation was also non-linear. This conflicts with the findings of Wellby et al., ${ }^{3}$ but is in agreement with the findings of Mincey et al. ${ }^{4}$ The problem is understandable if one considers what happens to the value of A.F.T-4 when T-4 is added to serum in vitro. As the binding sites approach saturation a given increment of T-4 produces a relatively greater increment in A.F.T-4. Examination of the law of mass action led us to plot $1 / \mathrm{T}-4$ against 1/A.F.T-4 in order to obtain a linear correlation between these two parameters. The result is shown in fig. 2 .

If we accept the findings of Wellby et al. ${ }^{3}$ that A.F.T-4 is linearly related to F.T.I., then since E.T.R. is not linearly related to A.F.T-4, E.T.R. cannot be linearly related to F.T.I. We are therefore not surprised at the finding of Dr. D'Haene and his colleages. It would be interesting to know if by plotting 1/E.T.R. against 1/F.T.I. the authors obtain a higher linear correlation than they have obtained at present.-We are, etc.,

A. M. B. Boss

D. KINGSTONE

Endocrine Unit,

New End Hospital,
London N.W.3

1 Thorson, S. C., et al., British Medical fournal, $1972,2,67$.

2 Sterling, K., and Brenner, M. A., Fournal of Clinical Investigation, 1966, 45, 153.

Wellby, M. L., O'Halloran, M. W. and Marshall, J., Clinica Chimica Acta, 1973, 45, 255.

Mincey, E. K., et al., fournal of Nuclear
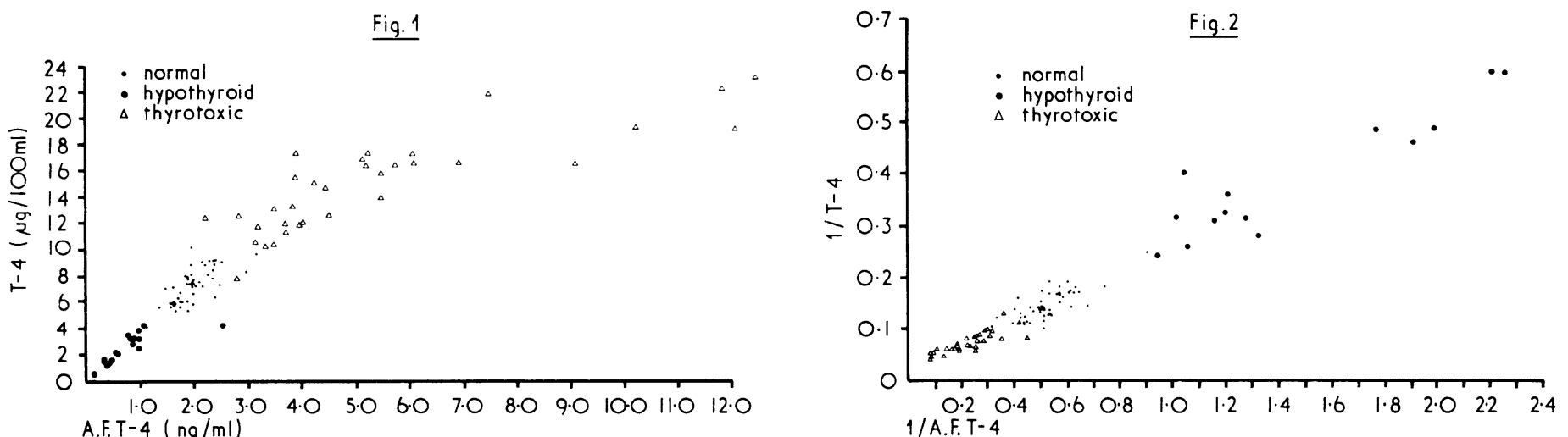